\title{
Studying Evidence Use for Health Policymaking from a Policy Perspective
}

\author{
Justin Parkhurst, Stefanie Ettelt, and Benjamin Hawkins
}

\section{INTRODUCTION}

Individuals working within the health sector very often see their work as guided by collectively shared normative values. In particular there is an overarching goal of improving people's health. Indeed the field of public health has been defined as "the science and art of preventing disease, prolonging life and promoting health through organized efforts of society" (Acheson 1988, p. 1). This is often linked, either implicitly or explicitly, to a concern for improving health equity (or reducing health inequalities) - for instance within the World Health Organization's calls to achieve 'health for all' (Detels and Tan 2015; Whitehead 1991). In recent decades, efforts to improve population health and to reduce health inequalities within countries and globally between states, have been linked with calls for evidence based policy (EBP). Drawing on the idea of evidence based

J. Parkhurst $(\bowtie)$

London School of Economics and Political Science, London, UK e-mail: j.parkhurst@Ise.ac.uk

S. Ettelt $\bullet$ B. Hawkins

London School of Hygiene and Tropical Medicine, London, UK e-mail: stefanie.ettelt@lshtm.ac.uk; ben.hawkins@lshtm.ac.uk

(C) The Author(s) 2018

J. Parkhurst et al. (eds.), Evidence Use in Health Policy Making, International Series on Public Policy, https://doi.org/10.1007/978-3-319-93467-9_1 
medicine (EBM), health policy actors see engagement with policy-relevant evidence to identify more effective, and by extension cost effective, interventions as the way to achieve their overarching policy objectives.

EBM as a concept is based on the idea that medicine should be practiced by making "conscientious, explicit, and judicious use of current best evidence in making decisions about the care of individual patients" (Sackett et al. 1996, p. 71). The origin of this idea is often attributed to Archie Cochrane, who wrote in the early 1970s about the need to use evidence of effectiveness to guide clinical practice (Cochrane 1972), although it was in 1993 that the formal establishment of the Cochrane Collaboration further served to provide both a global repository of evidence for specific clinical interventions, and an authority for best practices on how to review or select evidence to inform medical practice (Starr et al. 2009).

The notion of 'conscientious, explicit, and judicious' evidence use is relevant to consider in this context. From the earliest origins of the EBM movement, there was recognition that it is not necessarily appropriate to rely solely on research evidence when making decisions on diagnoses and medical treatment. Professional experience and judgement on the part of medical practitioners, in light of the evidence base and relevant inferences from this, remain important (Sackett et al. 1996). However, over time, the principles of EBM have gravitated towards specific types of evidence with clear preferences for certain study designs - encapsulated in so-called 'hierarchies of evidence' (Petticrew and Roberts 2003) - reflecting concerns about the internal validity of studies and the potential for biased outcomes that, in medicine, "routinely lead to false positive conclusions about efficacy" (Sackett et al. 1996, p. 72).

The EBM movement has, overall, been heralded as a triumph and is credited with ensuring that medical treatments produce beneficial results, particularly compared to the past, when many interventions were promoted solely on the basis of hypotheses of potential cause and effect that may, in fact, have been incorrect (Howick 2011). The Academy of Medical Royal Colleges, for instance, has argued that EBM "is the key to the success of modern Healthcare" (Sense About Science and Academy of Royal Medical Colleges 2013, p. 1), co-authoring a report providing examples of how EBM has improved health outcomes on a range of issues from HIV/ AIDS treatment to emergency allergy care and mental health treatment (Sense About Science and Academy of Royal Medical Colleges 2013).

The success of EBM has been seen by many authors as the inspiration for calls to expand the concept to other forms of decision making including 'evidence based policymaking' in health and other social policy areas 
(Berridge and Stanton 1999; Wright et al. 2007; Lin and Gibson 2003; Parkhurst 2017). This is despite recognition of the challenges in appropriating ideas from clinical practice and applying them to shape policymaking processes. For example, Black (2001) urged the medical community to 'proceed with care' with the idea of evidence based policy due to the qualitatively different nature of policymaking compared to medicine. A number of other authors have similarly argued that the political realities of policy decisions mean policy cannot simply be 'based' on evidence in the same way as clinical decisions and that the notion of a linear-rational relationship between evidence and policy is a fallacy (c.f. Lewis 2003; Hammersley 2005; Greenhalgh and Russell 2009).

Russell et al. (2008), for example, have explained that:

....academic debate on health care policy-making continues to be couched in the dominant discourse of evidence-based medicine, whose underlying assumptions - that policies are driven by facts rather than values and these can be clearly separated; that 'evidence' is context-free, can be objectively weighed up and placed unproblematically in a 'hierarchy'; and that policymaking is essentially an exercise in decision science. (p. 40)

These messages appear to have had only limited impact on the conceptual vocabulary of health policy making and scholarship. Despite these warnings, the language of 'evidence based policymaking' has become firmly established in health policy discourses, particularly in the United Kingdom (UK), Canada, and within many global health networks. As such, recent publications have continued to critique examples of the oversimplified or idealised embrace of evidence on which to 'base' policy (c.f. Hammersley 2013; Cartwright and Hardie 2012; Parkhurst 2017). In addition, recent systematic reviews have found limited engagement with the political nature of policymaking to help explain evidence use. Oliver, Innvaer, and Lorenc (2014a) concluded from one such review that while studies of evidence use have spread from health to other sectors, few works actually engage with aspects of the policy process or provide sufficient details to draw firm conclusions. In a related paper, the authors argue that:

The agenda of 'getting evidence into policy' has side-lined the empirical description and analysis of how research and policy actually interact in vivo. Rather than asking how research evidence can be made more influential, academics should aim to understand what influences and constitutes policy, and produce more critically and theoretically informed studies of decisionmaking. (Oliver et al. 2014b, p. 1) 
Another review by Liverani et al. (2013) (undertaken as part of the research programme making up this volume), similarly reviewed literature on evidence use related to health policymaking and found few examples that explicitly addressed politics to help explain the use of evidence to inform health policymaking.

Given this state of affairs, this book aims to contribute to a greater understanding of the political nature of policymaking and how it shapes the potential for, and resultant outcomes of, evidence use in health policymaking. In particular, we focus on scientific evidence arising from research and related systematic processes of data collection (e.g. data collection for monitoring the health system) as our principle subject. This is because, while we recognise that the term 'evidence' can take many meanings including personal experience and legal argumentation - it is the formal results of research activity and the application of the scientific method that have been seen as essential to the aspirations of both the EBM and the EBP movements.

We argue that while policy advocates have pursued their normative goals of improving health outcomes through 'better' policymaking, associated with reliance on research evidence, this has brought about a discourse that too narrowly focuses on certain conceptions of what counts as policy-relevant evidence. In addition, it overstates the role which evidence is able to play in the policy making process whilst paying insufficient attention to the politics of that process, including the competition of values, ideologies, and policy objectives which cannot themselves be determined by recourse to evidence.

There is thus a need to examine the complex interrelationship of evidence use and politics to form a more nuanced conception of the health policy process. This starts from an explicit recognition of the fundamentally political nature of the policy process that recognises that, while evidence can and should be an important factor informing policy debates, it cannot provide the sole basis for policy decisions or is usually insufficiently suited to resolve policy conflicts.

\section{The Multiple Meanings of 'Use' of Research Evidence}

The point of departure for developing our conceptualisation of how evidence informs policy is to start by questioning what it means to 'use' evidence in policymaking. Unlike clinical decision making, which often involves a choice between clearly circumscribed interventions for a fairly 
specific purpose (to improve patient outcomes), using evidence to inform policy usually does not fit this model. More often than not, policy is not a clearly delineated object, and there may be disagreement not just about the preferred policy 'solution', but also about the nature and definition of the problem to be addressed.

That evidence use in policymaking is not entirely compatible with notions of instrumental rationality has been known for some time. Indeed, Carol Weiss (1979) described a number of different meanings of research utilisation in the late 1970s. She discusses social science research more widely, but her models of research use are conducive to health policy research as well. In particular, she identifies seven variants of research utilisation, including a 'knowledge-driven' model in which basic research identifies new social problems; a 'political' model in which research is strategically used to achieve pre-existing goals; and an 'enlightenment' model in which research influences broader thinking more generally.

The model that perhaps best aligns with the current dominant rhetoric in the health sector, however, is Weiss' so-called 'problem solving' model of research utilisation, which sees direct application of a study's findings (for example findings from an evaluation of an intervention) to inform a specific policy decision (for example, a decision about which intervention to fund). Weiss, however, notes that it requires a tremendous, and incredibly rare, alignment of circumstances to see research used in this way. Indeed, this requires the identification, and agreement on the definition of a problem that policy and research are expected to address. In practice, of course, both problems and their solutions tend to be highly contested. For example, to some, health inequalities run counter to accepted norms of social justice and are thus identified as legitimate targets of government intervention, while for others inequalities are seen as the outcome of personal choices and thus beyond the remit of the state. Similarly, for some, governments are seen to have a responsibility to care for all, while for others government intervention in health is seen as an unwelcome overreach or intrusion on individual and market freedoms.

Contestation between groups who have different sets of values or beliefs in many ways is at the heart of many theories of policy change which perceive policymaking as a competitive process rather than a technocratic one (Sabatier 2007; John 1998). Yet it has been argued that the level and nature of these competitive environments can incentivise the manipulation of scientific or empirical evidence to achieve desired political goals (Parkhurst 2016). As a result, strategic, rather than instrumental 
uses of evidence appear commonplace in many policy arenas where political interests exist - often decried as 'policy-based evidence-making' and seen as a fundamental challenge to the ideal rational use of evidence that many social sector stakeholders champion (Marmot 2004; Strassheim and Kettunen 2014).

Nutley et al. (2007) have also provided a comprehensive mapping of many potential meanings of evidence use/utilisation that includes, but expands on Weiss' original concepts. They identify that "the most common image of research use is of an instrumental process that involves the direct application of research to policy and practice decisions" (p. 34). However, the authors detail a number of other ways to conceptualise research use beyond this simple view. This includes producing typologies of evidence use (similar to Weiss' (1979) model), as well as models which see practices of evidence use as a continuum from more conceptual to more instrumental uses, or instead considering evidence use as a process or series of stages rather than as one or more types.

These works highlight the limitations of instrumental approaches to evidence use, even if this continues to be held up as an ideal in many academic and professional circles. Yet mapping the different ways research and evidence are used does not, on its own, explains neither why we see different forms of evidence use arise at different times and in different contexts, nor what constitutes a 'good use of evidence' in particular policy areas. This is particularly important when reflecting on the specific goals of health sector actors, and the common belief across that sector about how robust use of evidence (and in particular of research evidence) will help to achieve those goals. In this volume we thus attempt to move forward from these initial mapping exercises to directly engage with the political nature of policymaking to reflect on how evidence is used within the health sector. This approach allows explicit consideration of the systems in place that work to provide evidence to policy decision makers, or seek to improve evidence use in some way.

\section{A Public Policy Perspective}

A public policy perspective on evidence use accepts that political dimensions of health policymaking will affect the relevance and use of evidence within those policy processes. Yet the policy sciences are a broad field, consisting of a wide range of theories and concepts that can each be used to provide insights into policy processes and outcomes. Thus 
calling for more public policy insights requires consideration of how precisely to apply this field of work to study evidence use in a comparative perspective.

Previous authors have engaged with theories of policy change to help explain when or how evidence might be used within policy processes. Yet what is apparent from these works is that there is a tremendous range of theories that could provide insights in one or another way to this question. Cairney (2016) highlights the relevance of a number of theories, frameworks, and approaches including: multiple streams theory, punctuated equilibrium theory, social constructionism, narrative frameworks, the advocacy coalitions framework, studies of policy transfer or diffusion, and complexity theory (see Cairney 2016, chapter 2). Cairney, however, embraces the usefulness of the concept of bounded rationality in particular, due to his work having a central focus on policy makers' perspectives and a need to overcome the comprehensive rationality underlying the evidence-based policymaking thinking. Smith (2013a) reviews many of the same theories as Cairney, including theories of policy change, but focuses on the 'power of ideas' to shape what is considered relevant evidence, and to affect the roles and actions of policy actors for two contrasting health policy issues: health inequalities and tobacco control.

The variety of policy studies theories thus provides a range of explanatory perspectives to consider different questions about policymaking and policy change. For example, if one was concerned with how evidence fits within ongoing processes of policy change, Kingdon's multiple streams approach or the Advocacy Coalitions Framework could be the most appropriate approaches to adopt. We are sympathetic to this wide variety of approaches and the insights they can provide into particular questions of evidence use.

However, in this volume we focus on two particular approaches derived from the policy sciences. First, we engage with the contested nature of policy decisions between multiple stakeholders who may be pursuing different interests, and conceptualising policy problems in different ways. Second we consider the influence of the political institutions that work to shape when and how particular forms of evidence influence policy decisions in different settings. Our decision to focus on these factors arose primarily from a desire to explore how the political nature of the policy process affects evidence use in different settings; as well as a desire to understand which forms of evidence use arise in different institutional contexts. 


\section{Politics as Power and Contestation}

One of the most widespread criticisms of calls for 'evidence based policymaking' comes from authors who point to the inherently contested nature of policy decisions. Unlike in clinical decision situations, policy is, as Lasswell (1990 [1936]) classically observed, about 'who gets what, when and how', emphasising the possibility of conflict over the distributive effects of policy. Ultimately, policy-making is about power and influence, and the ability of policy actors to generate or withhold support and influence an outcome. It is therefore not possible to separate policymaking from politics. Scholars have historically noted that policymaking represents decisions, made on behalf of society, to decide on what collective goals that society should pursue (Brecht 1959). As such it can be argued that these processes require some form of democratic legitimation that would typically be derived from ensuring that multiple interests are articulated or considered in the decision making process (even if some are excluded in the final choice of outcome) (Young 2000). In such a process, however, competing stakeholders participating in this process will seek to frame the terms of policy debates in way amenable to the objectives in order to shape decisions (Russell et al. 2008), with the recourse to 'evidence' serving as one mechanism through which policy discourses can be shaped in favour of (or against) a particular outcome.

In many instances there are wide asymmetries of power between different actors with obvious consequences for their ability to influence the definition of the policy problem, for example through issue framing, and the type of intervention put in place to address them (Lukes 2005). Transnational corporations, for example the global tobacco and alcohol industries, have enjoyed high degrees of success in shaping policy and the wider debates which surround policy decisions, not simply through direct lobbying, but through their use of media consultants, public relations and corporate social responsibility campaigns (Hawkins and Holden 2013).

The importance of issue framing in policy debates is thus critical to understand, both in relation to the construction of policy-relevant conceptualisations of evidence and in relation to what can be achieved by appeals to evidence in the context of highly contested policy debates. The framing of an issue can shape the way in which a policy problem is seen; the very essence of what it 'is' for the observer. This affects what the correct and legitimate policy response to this is considered to be, and thus what is identified as the most relevant body of evidence in assessing the policy 
problem under consideration and the proposed responses (c.f. Bacchi 2009; Fischer 2003). If we accept multiple, often mutually exclusive, framings of policy problems are possible, each claiming support from different (sometime overlapping) bodies of evidence, then the impossibility of settling policy dilemmas through recourse to the evidence becomes acutely apparent. This is why Russell et al. (2008) noted that it is 'naively rational' to assume that evidence can simply direct policy making in a linear way, with Hammersley (2013) going so far as to claim that 'evidence-based policy' is nothing more than a slogan used to discredit opponents.

Recognising the contested nature of decision making means that the specific form of issue contestation, the strength of relevant interests, the power of stakeholders and their networks, and their ability to frame problems and solutions, can be expected to play important roles in shaping how evidence is used within health policymaking processes. From this perspective, the actors involved in policymaking take centre stage analytically, with regard to the interest they may represent, the strategies they pursue and the behaviours they display to achieve their desired outcome. Focusing on contestation therefore allows for a deeper analysis of the role of actors, their interests, and agency. It also allows an alternative conceptualization of evidence use in policy processes. As Weiss $(1979,1991)$ already observed, actors can use evidence strategically or tactically to support a decision and to delegitimise other positions that are not supported by evidence (or by evidence of the same methodological robustness). Likewise, it is conceivable that evidence is used to build support and generate 'buy-in' and consensus, especially from audiences that are likely to support the notion that evidence should be a key ingredient of policymaking. In practice such efforts can fail as well as succeed. It will therefore be difficult to clearly separate different uses of evidence, which may be simultaneously instrumental and strategic.

Lines of contestation can be studied through a variety of case study types, including analysis of a single health issue in a single context; of multiple health issues in a single context; or for the same health issue in different contexts. We have examples of all of these within this volume. However, policy contestation is merely a starting point to apply the policy sciences to the study of evidence use, even with the depth of conceptual insights this initial step allows. Our driving interest was not only to look at single decision events or policy choices, but to consider longer term and systemic uses of evidence within the health sector. This means recognition that evidence use in decision making is not just a single occurrence or 
event, but rather it is an ongoing process integral to the policy process. Thus the second main component to our conceptual approach is to engage with concepts of institutionalism in order to explore how institutions shape and direct the ongoing use of evidence affecting health decisions across multiple decision points and over longer time frames.

\section{An Institutional Perspective to Analyse Evidence Use in Policy Processes}

Lowndes and Roberts (2013) posit that "[i]nstitutions are central to the subject matter of political analysis (p. 1)," and, indeed, institutional analysis is well established in the fields of political analysis and international public policy comparisons, including comparisons of health systems and reforms (Immergut 1992; Tuohy 1999). Given its history with EBM, many look to the health sector in particular as leading other social sectors in its engagement with evidence use (Parkhurst 2017); but even in this field, only a small number of studies to date have directly analysed institutions in relation to evidence use for policy. Some of these have focussed on organisational arrangements that facilitate or hinder the uptake of pieces of evidence; for example in relation to drug policy in England and Scotland (Nutley et al. 2002), in health inequality policy in England (Smith 2013b), or, in relation to clinical practice, in routine nursing practice in US hospitals (Stetler et al. 2009). The interest in organisational arrangements is also reflected in some current work on organisational 'embeddedness' of evidence use as well within health policymaking bodies (c.f. Gonzales-Block 2013; Koon et al. 2013). Other work has looked at institutionalised processes of evidence use to inform fairly circumscribed sub-fields of health policy, such as coverage decisions relating to publicly funded health services and pharmaceuticals, with the use of health technology assessment (HTA) a prominent example (Garrido 2008; Turchetti et al. 2010).

However, our own systematic review of studies on evidence use, could find only a limited engagement with the concept of institutions, especially political institutions relevant to policymaking, to help explain the use of evidence in policymaking in the health-related literature (Liverani et al. 2013). This echoes an earlier finding by Nutley et al. (2002), who looked at public policy more broadly and concluded that "insufficient attention has been paid to the institutional arrangements for connecting research (and other evidence) to policy (p. 77)." 
Therefore, we find that a significant gap in the literature still exists to consider institutions more directly in relation to their role in shaping evidence use for health policy making. In this volume, we draw on the broader concepts typical of new institutionalism, as explored by authors such as Peters $(2005,2008)$ and Lowndes and Roberts $(2013)$, who see new institutionalism as a way to move beyond historical work that focussed solely on formal arrangements of political systems, to additionally consider how institutional rules, practices, and narratives work to shape policy actor behaviour.

From this perspective, and based on the analyses in the chapters that follow, we stipulate that institutional structures, norms, practices, and narratives will influence evidence use in policymaking in two ways. First, institutional arrangements will shape the processes of policymaking and thus determine which actors have access to policy and whose positions are considered relevant or legitimate. This can be formal, for example through stipulations as to who will be involved any given policy decision, or informal, with actors having an implicit understanding, or a shared perception, of the appropriateness of who should be involved in and who excluded from the decision process. This focus on the roles of key policy actors helps to capture the institutionalised features of policy contestation in different settings, akin to what Peters (2005) describes as a rational choice branch of new institutionalism which maintains a focus on policy actors pursuing their interests within institutional arrangements. We have used this perspective in a number of different countries to analyse how different institutional arrangements influence which stakeholders bring evidence of different kinds to policy processes, often in the pursuit of particular interests.

Second, efforts to improve the use of evidence in policymaking can themselves lead to the creation of new structures, rules, practices, and narratives that inform future policy decisions, i.e. evidence utilisation of one form or another can become institutionalised, described elsewhere as 'governing' how evidence is used (c.f. Hawkins and Parkhurst 2015; Parkhurst 2017). For example, governmental or non-governmental bodies have been set up in countries with the explicit aim of generating, assessing or synthesising evidence to develop a more consistent (and often a more instrumental) approach to evidence use in policy. In order to exercise their mandate, these bodies have, over time, created a set of rules and practices that guide how they execute their mandates and go about their tasks. These rules and practices are typically accompanied by ideas about the 'right' types of evidence (e.g. the 'hierarchy of evidence'), methods of 
appraisal and synthesis, and ways of using them in decision-making (c.f. Sutherland 2001; Petrisor and Bhandari 2007; Evans 2003; Borgerson 2009). Bodies such as these also operate with a legal framework set by government or legislatures, which can lead to instances where their decisions may be challenged or overridden by other political institutional structures (c.f. Chap. 5 in this volume and Ettelt forthcoming).

Critically exploring these concepts can utilise what Peters (2005) describes as normative institutionalism, which applies ideas such as March and Olsen's $(1989,2006)$ 'logics of appropriateness'. This concept is in many ways the antithesis of rational choice perspectives that see individuals as pursuing their own interests, and instead explores how, within institutional arrangements, individuals work towards outcomes guided by collective normative principles of what is seen to be the correct thing to do, or what is the right outcome to achieve. This can therefore be used to explore how practices play out within key administrative bodies in relation to dominant ideas about evidence use (or about evidence-based policymaking) within the health sector; and further allows consideration of how alternative logics play out when health related policymaking takes place across institutions and policy sectors with their own distinct normative goals.

Institutions can be formal and informal, as well as explicit and implicit, which means that at times they can be difficult to pin down analytically or observe empirically. Yet all permutations may play out in important ways to shape evidence use in different political contexts. Rules such as legislation would be at the formal, explicit end of the spectrum, while narratives and discourses about which behaviours of policy actors are appropriate are more likely to be informal (and potentially implicit). In combination, institutional elements form structures and logics that shape how actors behave, how they relate to each other, and how they relate to policy processes, both individually and collectively. Ultimately these factors can play important roles in shaping which of the many forms of evidence use arise in different health policy processes - be it instrumental uses in line with idealised views of the health community, strategic uses by policy actors to pursue their interests, or some other form or combination of the types of evidence use.

\section{Outline OF THE BoOK}

The remainder of this book presents a set of chapters consisting of country case studies and comparative analyses that arose from a five-year research project supported by the European Research Council entitled 'Getting 
Research into Policy in Health' (the GRIP-Health project). The project aimed to improve the understanding and practices of evidence use by examining health policy processes in six countries cutting across low, middle, and high income settings, as well as varying in their geographic location and administrative arrangements. Specifically cases come from Cambodia, Colombia, Ethiopia, Germany, Ghana, and the United Kingdom (analysed as the UK in Chap. 7, but more narrowly focussing on England in other comparative chapters).

The first set of chapters presents findings from individual countryfocussed investigations. These examined one or more health policy topics, as well as processes of decision making, with explicit consideration of the contestation of the issues and/or the institutional arrangements in place that end up affecting the use of evidence.

Chapter 2 presents the first of our country examples with a case study from Cambodia that specifically looks at the differences in evidence use for three contrasting health policy issues - HIV/AIDS, tobacco control, and performance based financing of midwifery services. The chapter illustrates that despite the broad rhetorical embrace of the concept of evidence based policymaking within the health sector, the extent to which evidence is used in instrumental ways can vary substantially depending on the political realities of specific policy topics, including competing governmental interests in issues or the conceptual framing about what evidence is meant to achieve in different cases. The chapter considers the differing logics of actors in each policy process and how these shape evidence use for different health issues.

Chapter 3 follows with an analysis from Ethiopia that looks specifically at the challenges to multisectoral planning for nutrition in that country. It continues the concern over logics of appropriateness in relation to evidence use by reflecting on how different sectors (health, agriculture, finance, etc.) may see their goals and thus their perceptions of policy relevant evidence in different ways. The chapter also reflects on the constructed nature of the framing of nutrition policy in the country, which could reflect competing goals between differing policy sectors. Overall it considers how these features make multisectoral planning, and the use of evidence within such planning, a challenge.

Chapter 4 presents a case from Ghana that, rather than looking at a specific policy topic, focusses on a key part of the evidence advisory system of the country. Specifically, the Chapter investigates the institutional system in place which dictates how routine local data is used to inform annual 
health sector planning and policy reviews. The chapter considers how the data and evidence review process has been institutionalised in ways that not only shape which data and pieces of evidence inform certain planning activities, but which also may have governance implications in terms of the systems of accountability in the country, and the role or influence of international funding agencies.

In Chap. 5, a case study in Colombia further expands the institutional lens to look more broadly at the role of the legislature within ongoing health systems reform debates. The chapter also engages directly with the importance of policy contestation in shaping when evidence will, or will not, have a role in influencing legislative outcomes. The analysis illustrates that even though scientific evidence was found to be available to decision makers, it was unable to provide common ground or positions of compromise within the highly contested and fragmented health policy field.

Chapter 6 presents a case study from Germany that particularly explores the instrumental and strategic uses of evidence to inform debates about minimum service volumes in hospitals (i.e. whether facilities should have to provide a minimum number of procedures to be allowed to offer the service). The analysis illustrates how the interests of key actors can lead to strategic uses of evidence, but further highlights the dynamic relationship between evidence use and the political and institutional context, exploring how the legislative nature of policy-making, corporatism, and the role of the judiciary in Germany influence these uses of evidence in this case.

The final country case study in this section comes in Chap. 7 presenting the case of electronic cigarette policy in the UK. This case study focuses on the contested nature of policy debates, but further considers the importance of how alternative constructions or framings of the policy issue itself by competing groups may help to explain how evidence is used. The chapter then discusses why appeals to particular forms of evidence do not have the impact that many health actors might expect. It concludes by reiterating a core theme of this volume that the political nature of policy debates must be engaged with explicitly to understand evidence use for health policymaking.

Following these country specific chapters, we present a set of three comparative analyses that draw lessons from across multiple country cases to address key themes arising from the project. Chapter 8 begins with a direct consideration of the institutional systems in place that work to provide evidence to inform decision making by Ministries of Health. It begins by considering the roles that Ministries of Health have as stewards of national health care, considering how this can also extend to having a 
mandate to shape the evidence advisory systems which will inform health policy decisions. It then looks across all six of our country cases to consider whether such systems provide relevant information in a timely manner to key decision points. The chapter illustrates how key structural and practical differences exist between countries, and also notes that, at times, key health decisions lie outside the authority of Ministries of Health, providing further challenges to the roles that formalised evidence advisory systems might play to inform those decisions.

This recognition of non-ministerial authority over health decisions leads directly to Chap. 9, which discusses insights about the roles of legislatures and the judiciary in shaping evidence use for health decisions. The chapter draws out lessons from multiple country case studies to illustrate the different ways that these bodies may use evidence to classic ideas of instrumental or problem-solving use embraced by many health sector actors. Ultimately the chapter draws out just how different evidence use can look within national policy processes based on existing institutional systems embedded in the legal or constitutional frameworks of countries.

Chapter 10 presents the final comparative chapter, drawing lessons on evidence use in relation to the role and potential influence of international aid donors in our lower-income, aid-dependent case study countries (Ethiopia, Cambodia, and Ghana). The chapter draws out the importance of factors such as: the levels of local technical capacity, differing stakeholder framings of issues, and the influence of external actors on underlying systems of decision making. The chapter discusses how these were seen to affect which evidence was used and for what purposes - illustrating how the broader political economy of aid and development can play out in multiple ways in terms of evidence use in health policymaking.

Finally, Chap. 11 provides a discussion chapter that allows us to reflect on the issues raised in this introduction. We revisit what our cases show in terms of the many meanings of research utilisation, and consider what has been learned in terms of how political and institutional factors shape the form of evidence use arising in health policy processes. The chapter synthesises insights about how political contestation, issue construction, and institutional arrangements all work (and at times work together) to shape and direct evidence use. The chapter, however, concludes by recognising that the insights from this volume only present a starting point to understanding the politics of evidence use from a public policy perspective, merely scratching the surface of the many areas of research that can further be done in this field. 


\section{REFERENCES}

Acheson, Donald. 1988. Public health in England. Report of the Committee of Inquiry into the future development of the public health function, The Stationary Office, London.

Bacchi, Carol Lee. 2009. Analysing policy: What's the problem represented to be? Frenchs Forest NSW: Pearson Australia.

Berridge, V., and J. Stanton. 1999. Science and policy: Historical insights. Social Science \& Medicine 49 (9): 1133-1138.

Black, Nick. 2001. Evidence based policy: Proceed with care. British Medical Journal 323: 275-279.

Borgerson, Kirstin. 2009. Valuing evidence: Bias and the evidence hierarchy of evidence-based medicine. Perspectives in Biology and Medicine 52 (2): 218-233.

Brecht, Arnold. 1959. Political theory: The foundations of twentieth-century political thought. Princeton: Princeton University Press.

Cairney, Paul. 2016. The politics of evidence-based policymaking. London: Palgrave Pivot.

Cartwright, N., and J. Hardie. 2012. Evidence-based policy: A practical guide to doing it better. Oxford: Oxford University Press.

Cochrane, Archibald Leman. 1972. Effectiveness and efficiency: Random reflections on health services. Vol. 900574178. London: Nuffield Provincial Hospitals Trust.

Detels, Roger, and Chorh Chuan Tan. 2015. The scope and concerns of public health. In The Oxford handbook of global public health, ed. Roger Detels, Martin Gulliford, Quarraisha Abdool Karim, and Chorh Chuan Tan, 6th ed., 3-18. Oxford: Oxford University Press.

Ettelt $S$. forthcoming. Access to treatment and the constitutional right to health in Germany: A triumph of hope over evidence? Health Economics, Policy and Law.

Evans, David. 2003. Hierarchy of evidence: A framework for ranking evidence evaluating healthcare interventions. Journal of Clinical Nursing 12 (1): 77-84. https://doi.org/10.1046/j.1365-2702.2003.00662.x.

Fischer, Frank. 2003. Reframing public policy. Oxford: Oxford University Press.

Garrido, Marcial Velasco. 2008. Health technology assessment and health policymaking in Europe: Current status, challenges and potential. Copenhagen: WHO Regional Office Europe.

Gonzalez-Block, M.A. 2013. Reflections on Health Policy and Systems Research embeddedness. Presentation at Alliance for Health Policy and Systems Research at the Harvard School of Public Health, May 9.

Greenhalgh, Trisha, and Jill Russell. 2009. Evidence-based policymaking: A critique. Perspectives in Biology and Medicine 52 (2): 304-318.

Hammersley, Martyn. 2005. Is the evidence-based practice movement doing more good than harm? Reflections on Iain Chalmers' case for research-based policy making and practice. Evidence \& Policy: A Journal of Research, Debate and Practice 1 (1): 85-100. 
2013. The myth of research-based policy and practice. London: Sage.

Hawkins, Benjamin, and Chris Holden. 2013. Framing the alcohol policy debate: Industry actors and the regulation of the UK beverage alcohol market. Critical Policy Studies 7 (1): 53-71.

Hawkins, Benjamin, and Justin Parkhurst. 2015. The 'good governance'of evidence in health policy. Evidence \& Policy: A Journal of Research, Debate and Practice 12 (4): 575-592.

Howick, Jeremy. 2011. The philosophy of evidence-based medicine. Oxford: Wiley-Blackwell.

Immergut, Ellen M. 1992. Health politics: Interests and institutions in Western Europe. Cambridge: Cambridge University Press.

John, Peter. 1998. Analysing public policy. London: Continuum.

Koon, Adam D., Krishna D. Rao, Nhan T. Tran, and Abdul Ghaffar. 2013. Embedding health policy and systems research into decision-making processes in low-and middle-income countries. BMC Health Research Policy and Systems 11 (1): 30.

Lasswell, Harold Dwight. 1990 [1936]. Politics; who gets what, when, how. Gloucester: Peter Smith Publisher.

Lewis, Jenny M. 2003. Evidence-based policy: A technocratic wish in a political world. In Evidence-based health policy: Problems \& possibilities, ed. Vivian Lin and Brendan Gibson, 250-259. Oxford: Oxford University Press.

Lin, Vivian, and Brendan Gibson. 2003. Introduction. In Evidence-based health policy: Probelems and possibilities, ed. Vivian Lin and Brendan Gibson, xvii-xxvi. Oxford: Oxford University Press.

Liverani, Marco, Benjamin Hawkins, and Justin O. Parkhurst. 2013. Political and institutional influences on the use of evidence in public health policy. A systematic review. Plos One 8 (10): e77404.

Lowndes, Vivien, and M. Roberts. 2013. Why institutions matter. Basingstoke: Palgrave.

Lukes, Stephen. 2005. Power, a radical view. 2nd ed. Houndsmills/Basingstoke: Palgrave Macmillan.

March, James G., and Johan P. Olsen. 1989. Rediscovering institutions: The organisational basis of politics. New York: The Free Press.

- 2006. The logic of appropriateness. In The Oxford handbook of public policy, ed. Michael Moran, Martin Rein, and Robert E. Goodin, 689-708. Oxford: Oxford University Press.

Marmot, Michael G. 2004. Evidence based policy or policy based evidence? Willingness to take action influences the view of evidence - Look at alcohol. British Medical Journal 328: 906-907.

Nutley, Sandra, Isabel Walter, and Nick Bland. 2002. The institutional arrangements for connecting evidence and policy: The case of drug misuse. Public Policy and Administration 17 (3): 76-94.

Nutley, Sandra M., Isabel Walter, and Huw T.O. Davies. 2007. Using evidence: How research can inform public services. Bristol: The Policy Press. 
Oliver, Kathryn, Simon Innvaer, Theo Lorenc, Jenny Woodman, and James Thomas. 2014a. A systematic review of barriers to and facilitators of the use of evidence by policymakers. BMC Health Services Research 14 (1): 2.

Oliver, Kathryn, Theo Lorenc, and Simon Innvaer. 2014b. New directions in evidence-based policy research: A critical analysis of the literature. Health Research Policy and Systems 12 (1): 34.

Parkhurst, Justin. 2016. Appeals to evidence for the resolution of wicked problems: The origins and mechanisms of evidentiary bias. Policy Sciences 49 (4): 373-393. https://doi.org/10.1007/s11077-016-9263-z.

- 2017. The politics of evidence: From evidence based policy to the good governance of evidence. Abingdon: Routledge.

Peters, Guy. 2005. Institutional theory in political science. London: Continuum.

Peters, B. Guy. 2008. Institutional theory: Problems and prospects. In Debating institutionalism, ed. Jon Pierre, B. Guy Peters, and Gerry Stoker, 1-21. Manchester: University of Manchester Press.

Petrisor, B.A., and M. Bhandari. 2007. The hierarchy of evidence: Levels and grades of recommendation. Indian Journal of Orthopaedics 41 (1): 11.

Petticrew, Mark, and H. Roberts. 2003. Evidence, hierarchies, and typologies: Horses for courses. Journal of Epidemiology and Community Health 57 (7): 527-529.

Russell, Jill, Trisha Greenhalgh, Emma Byrne, and Janet McDonnell. 2008. Recognizing rhetoric in health care policy analysis. Journal of Health Services Research \& Policy 13 (1): 40-46. https://doi.org/10.1258/ jhsrp.2007.006029.

Sabatier, Paul A. 2007. Theories of the policy process. 2nd ed. Boulder: Westview Press.

Sackett, David L., William M.C. Rosenberg, J.A. Muir Gray, R. Brian Haynes, and W. Scott Richardson. 1996. Evidence based medicine: What it is and what it isn't. British Medical Journal 312: 71-72.

Sense About Science, and Academy of Royal Medical Colleges. 2013. Evidence based medicine matters. London: Sense About Science.

Smith, Katherine. 2013a. Beyond evidence based policy in public health: The interplay of ideas. Basingstoke: Palgrave Macmillan.

- 2013b. Institutional filters: The translation and re-circulation of ideas about health inequalities within policy. Policy \& Politics 41 (1): 81-100.

Starr, Mark, Iain Chalmers, Mike Clarke, and Andrew D. Oxman. 2009. The origins, evolution, and future of The Cochrane Database of Systematic Reviews. International Journal of Technology Assessment in Health Care 51 (Supplement 1): 182-195.

Stetler, C.B., J.A. Ritchie, J. Rycroft-Malone, A.A. Schultz, and M.P. Charns. 2009. Institutionalizing evidence-based practice: An organizational case study using a model of strategic change. Implement Science 4: 78. https://doi. org/10.1186/1748-5908-4-78. 
Strassheim, Holger, and Pekka Kettunen. 2014. When does evidence-based policy turn into policy-based evidence? Configurations, contexts and mechanisms. Evidence \& Policy: A Journal of Research, Debate and Practice 10 (2): 259-277. https://doi.org/10.1332/174426514X13990433991320.

Sutherland, Susan E. 2001. The evidence hierarchy. Journal of the Canadian Dental Association 67: 375-378.

Tuohy, Carolyn Hughes. 1999. Accidental logics: The dynamics of change in the health care arena in the United States, Britain, and Canada. Oxford: Oxford University Press.

Turchetti, Giuseppe, Enza Spadoni, and Eliezer Geisler. 2010. Health technology assessment. IEEE Engineering in Medicine and Biology Magazine 29 (3): $70-76$.

Weiss, Carol H. 1979. The many meanings of research utilization. Public Administration Review 39 (5): 426-431.

- 1991. Policy research: Data, ideas, or arguments. In Social sciences and modern states: National experiences and theoretical crossroads, ed. Peter Wagner, Carol Hirschon Weiss, Björn Wittrock, and Hellmut Wollmann, 307-332. Cambridge: Cambridge University Press.

Whitehead, Margaret. 1991. The concepts and principles of equity and health. Health Promotion International 6 (3): 217-228. https://doi.org/10.1093/ heapro/6.3.217.

Wright, John S.F., Jayne Parry, and Jonathan Mathers. 2007. 'What to do about political context?' Evidence synthesis, the New Deal for Communities and the possibilities for evidence-based policy. Evidence \& Policy: A Journal of Research, Debate and Practice 3 (2): 253-269.

Young, Iris Marion. 2000. Inclusion and democracy. Oxford: Oxford University Press.

Open Access This chapter is licensed under the terms of the Creative Commons Attribution 4.0 International License (http://creativecommons.org/licenses/ by $/ 4.0 /$ ), which permits use, sharing, adaptation, distribution and reproduction in any medium or format, as long as you give appropriate credit to the original author(s) and the source, provide a link to the Creative Commons license and indicate if changes were made.

The images or other third party material in this chapter are included in the chapter's Creative Commons license, unless indicated otherwise in a credit line to the material. If material is not included in the chapter's Creative Commons license and your intended use is not permitted by statutory regulation or exceeds the permitted use, you will need to obtain permission directly from the copyright holder.

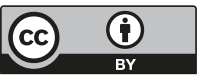

